\title{
Treadmill integrated robot-assisted ankle dorsiflexion training for stroke rehabilitation: $A$ randomized controlled trial
}

\section{Susan Conroy ( $\sim$ susan.conroy@va.gov )}

Baltimore VA Medical Center https://orcid.org/0000-0002-1505-3071

\section{Anindo Roy}

University of Maryland

\section{Laurence Magder}

University of Maryland Department of Epidemiology and Public Health

Derek Eversley

VA Maryland Health Care System

\section{Kate Flores}

Baltimore VA Medical Center

\section{Zachary Kerns}

Baltimore VA Medical Center

\section{Steven Kittner}

University of Maryland School of Medicine

\section{Richard Macko}

VA Maryland Health Care System

\section{Short report}

Keywords: Stroke, hemiparetic gait, ankle robot, locomotor training

Posted Date: April 6th, 2020

DOI: https://doi.org/10.21203/rs.3.rs-20686/v1

License: (1) This work is licensed under a Creative Commons Attribution 4.0 International License. Read Full License 


\section{Abstract}

Background: Stroke-related ankle dysfunction due to hemiparesis has a profound negative impact on gait biomechanics and walking. Task-oriented treadmill training improves gait velocity but does not lead to restitution of ankle function. Advances in robotic technology have led to the development of an adaptive ankle robot that can be integrated into treadmill walking and provide precisely timed graded assistance consistent with motor learning approaches. The aim of this study was to compare the effectiveness of a 6-week treadmill-integrated adaptive ankle robot (TMR) training to 6-weeks of treadmill training (TM) alone on improved paretic ankle motor control and gait performance.

Methods: This was a single-blind (evaluator-blinded) randomized controlled trial. 45 participants received either TMR or TM training 3 times per week for 6 weeks. Primary outcomes were improved peak paretic ankle dorsiflexion (DF) angle at swing, improved DF angle at foot strike (weight acceptance), and increased gait velocity during self-selected over-ground walking. The primary analysis was based on intention-to-treat using a longitudinal regression model. An additional sub-set analysis of subjects with biomechanically defined foot drop was performed.

Results: There were no significant post-training ankle dorsiflexion or gait velocity differences between groups. Six-week post-training mean peak paretic DF swing angle was $(4.84 \pm 6.83 ; 4.2 \pm 6.83 p=0.63)$ and DF angle at foot strike was $(-0.70 \pm 6.55 ;-0.46 \pm 5.70 p=0.84)$ respectively for TMR and TM. Gait velocity gains were similar and TMR had a mean increase of $0.54 \mathrm{~m} / \mathrm{s} \pm 0.24$ and TM increased $0.56 \mathrm{~m} / \mathrm{s}$ \pm 0.32 . $p=0.48$ post-training.

Conclusion: Integrating adaptive ankle robotics into task-specific locomotor training was not significantly better than treadmill training alone. Both interventions improved gait velocity. Promising results in ankle motor control were seen in a subset of subjects with biomechanically defined foot drop that warrants further investigation. Keywords: Stroke, hemiparetic gait, ankle robot, locomotor training Clinical trials.gov id: NCT02483676. Registered June 29, 2015, https://clinicaltrials.gov/ct2/show/NCT02483676

\section{Introduction}

Stroke is the leading cause of long-term adult disability and ankle dysfunction due to hemiparesis has a profound impact on gait efficiency, velocity, and balance [1,2]. The ankle is a major biomechanical contributor to normal gait and hemiparetic deficits often lead to stance and swing phase asymmetries [3,4]. Impaired ankle dorsiflexion control or foot drop occurs in $30 \%$ of survivors [5] limiting one's ability to safely clear the foot off the ground or appropriately control positioning for weight acceptance. Hemiparetic gait deficits contribute to postural instability resulting in more than $70 \%$ of patients falling within the first 6 months of onset and an increased likelihood of hip or wrist fracture in the first year [6,7]. Conventional interventions to mitigate ankle deficits are labor-intensive due to difficulties providing appropriate assistance, timing and intensity in the gait cycle to achieve a therapeutic effect [8]. As such, current foot drop management is limited to external support via an ankle foot orthosis (AFO) or functional 
electrical stimulation (FES). These interventions can improve safety and gait speed, but neither is proven to address the underlying ankle neuromotor deficits or facilitate motor learning for functional independence when not worn [5, 9-11].

Among the unknowns is whether shaping neuromotor control specifically across the ankle joint could have a lasting therapeutic impact on the whole-task function of independent walking. Advances in robotic control systems such as impedance control [12] to mediate human-robotic cooperative learning and the development of modular wearable therapeutic devices capable of incorporating sensor feedback and detect the wearer's walking intention $[13,14]$ provide an opportunity to test this question. Previous lower extremity motor learning-based approaches studied task-specific locomotor treadmill training with and without partial body weight support with varying success $[15,16]$. Likewise, lower extremity robotic exoskeletons have had a positive impacted on selected gait outcomes, but do not incorporate the ankle in the robotic actuation $[17,18,19]$ and have not shown an advantage over an equal dose of standard therapy in a large multi-center trial or recent scoping review $[20,21]$.

Several studies demonstrate the immediate benefit of robot-assisted ankle dorsiflexion to improve foot drop [22-24]. However, few studies investigated the therapeutic effect of joint-specific human-robotic cooperative learning to improve walking when the ankle robot is removed [13]. A seated robot-assisted ankle training paradigm using impedance control showed improved paretic ankle motor function in both chronic and early stroke recovery phases $[25,26]$ and had a small positive effect on unassisted overground (OG) walking. More recent findings suggest treadmill-based adaptive control ankle robotics to be more effective than seated to improve unassisted gait in chronic hemiparetic stroke [27]. Embedding impedance control within an adaptive control architecture during locomotor treadmill training for precisely time graded ankle assistance at critical gait cycle sub-events may facilitate sensorimotor relearning for a greater therapeutic effect.

This study sought to investigate whether integrating dorsiflexion robotic assistance at the ankle during treadmill walking can lead to improved ankle function and gait velocity compared to treadmill training alone. Our hypothesis was that treadmill-integrated ankle robot (TMR) training would improve dorsiflexion and walking function more than treadmill training alone (TM) and that durable benefits would be seen 6-weeks post-training. This study investigated the comparative effectiveness of 6-weeks of TMR versus TM using primary outcome measures of improved peak paretic ankle dorsiflexion (DF) angle at swing phase and foot strike (weight acceptance), and an increase in self-selected OG gait velocity.

\section{Methods}

\section{Subjects}

Recruitment occurred between September 2015 through April 2019. Forty-five stroke survivors (28 males and 17 females) met all eligibility criteria and were randomized in this parallel randomized controlled trial after baseline data collection to receive either treadmill robot training using the ankle robot (TMR) or 
treadmill training alone (TM). Inclusion criteria was as follows: (1) index stroke $>2$ months prior to enrollment with residual lower extremity hemiparesis including symptoms of foot-drop (2) clear indications of hemiparetic gait assessed by clinical observation; (3) completion of all conventional physical therapy; and (4) ability to walk on a treadmill with handrail support. Individuals with unstable angina, heart failure within the last 3 months, poorly controlled hypertension, a recent hospitalization for a severe medical condition, orthopedic or chronic pain, a history of orthopedic related gait problems or severe aphasia limiting informed consent were excluded from the study. All participants signed informed consent and underwent medical evaluations to establish eligibility.

Randomization was based on permuted blocks in two strata defined by baseline gait speed and the study statistician sent the computer-generated allocation to the study coordinator. Subjects were expected to participate 3-times weekly in their randomized 6-week gait training program. Recruitment and informed consent procedures were approved by the University of Maryland, Baltimore Institutional Review Board and the Baltimore Veterans Affairs Research and Development Committee.

\section{Data Collection}

Assessments were completed in the research lab by trained research staff blinded to randomization assignment at baseline, post training, 6-weeks post training and 3-months post training. Gait assessments were performed over two separate days and consisted of the Timed 10-Meter Walk Test (10MWT) [28], lower limb joint kinematic data collection and paretic leg force generation during OG walking. Three 10MWT were performed on the first visit using an instrumented gait mat (GAITRite ${ }^{\circledR}$, CIR Systems, Havertown, Pa). to determine self-selected OG walking velocity with or without an assistive device as needed. Spatiotemporal outcomes of mean speed $(\mathrm{cm} / \mathrm{s})$, stride lengths $(\mathrm{cm})$, cadence (steps/min), and relative times in paretic single support and double support (\%-cycle) were collected. The speed for all the walking conditions were based upon this initial self-selected floor walking velocity. To minimize fatigue, participants had a two-day rest prior to returning for additional walking tests.

A robot-based evaluation was completed during this second visit. Participants practiced walking with the robot as needed to adapt to its weight prior to data collection. Neutral stance alignment of the lumbosacral (L5/S1) joint, bilateral anterior superior iliac spine, knee joint, ankle joint, and feet was measured and collected before the robot and non-robot wearing OG trials using Vicon Nexus motion analysis system. All kinematic variables were expressed with respect to this neutral stance or "zero" angle. Once captured, participants walked with and without the robot across a 7.3-meter-long walkway at their self-selected walking pace. Footswitches (Myopac Jr., Run Technologies, Mission Viego, CA) inside the shoes determined robotic timing of paretic foot initial contact and pre-swing termination during the gait cycle. The calculated OG velocity while wearing the robot was utilized to set the treadmill speed for both TMR and TM treadmill conditions. Additional robot-based ankle metrics and positional data were collected during seated unassisted ankle robot trials as described elsewhere [25].

On this second visit non-robotic assessments included paretic leg anterior-posterior (A-P) propulsive force generation in single-leg support during self-selected speeds over a force plate (data not presented 
here). Additionally, three-dimensional motion analysis calculations were generated during the walking trials based on retro-reflective markers on the anterior and posterior iliac spine, lateral mid-thigh, lateral mid-gastrocnemius, lateral aspect of the foot, and the toe and heel of each leg.

\section{Intervention}

Interventions were initiated by matching treadmill gait training speeds with baseline assessments and were advanced with a performance-based progression over 18 sessions ( $3 x /$ week; 6 weeks). Participants were supervised throughout training and encouraged to exert a work intensity effort between a range of "somewhat hard-to-hard" on the Borg Rating of Perceived Exertion Scale [29]. Each one-hour session included AFO use if needed for the TM group and removal of the AFO for the TMR robot-assisted training. An impedance-controlled ankle robot (Anklebot; Interactive Motion Technologies; Watertown, MA) actuated ankle dorsiflexion as described in the literature [30] during the TMR locomotor training. Robot assistance was individualized based on dorsiflexion ankle deficits, and pre-training spatial-temporal gait cycle values. The treadmills were all equipped with a body weight support harness for safety in the advent of loss of balance and the robot set-up included an adjustable shoulder strap to offset the robot's weight and provide anti-gravity support during the swing phase of walking.

\section{Data Analysis}

The analysis was pre-specified and primary outcome variables were peak paretic DF swing angle, DF angle at foot strike, and gait velocity. The groups were compared with respect to these outcomes using a longitudinal regression model with the outcomes measured at four time points (baseline, post training, 6weeks post training, and 3 months post training). The model allowed for different variances at each time point in each group, and an unstructured within-person correlation pattern [31] and was fit by restricted maximum likelihood. An advantage of this approach over repeated measures ANOVA is that it makes fewer assumptions about the variance structure, it allows for inclusion of those with missing data at some time points, and it implicitly imputes missing values. Due to the randomization, the model incorporated the assumption that the groups were equivalent in expectation at baseline.

The primary analysis was based on the principle of intention to treat (ITT). However, since some of the participants did not contribute any data (baseline or follow-up) for the primary outcomes, these participants were not included in the primary analysis, making this a modified ITT analysis. In a secondary analysis, we compared groups defined by the treatment they actually received. In this "as treated" (AT) analysis, we excluded those who did not participate in at least 6 exercise sessions and we crossed one patient over who had been randomized to receive TM, but actually received TMR. The minimum number of sessions was based on motor learning profiles of the unassisted peak paretic swing angle across 18 training sessions by Forrester et al. where at least 6 session were required for subjects to attain $80 \%$ of their steady-state post-training value [27]. Additionally, in an exploratory analysis, we restricted the analysis to those who satisfied a biomechanical definition of foot drop This included those with a negative paretic peak DF swing angle on their baseline OG Vicon gait assessment. Eight subjects 
(6 randomized to TMR; 2 randomized to TM) met this definition. Biomechanical foot drop was defined as peak DF swing angle less than $0 \mathbb{Q}$ at swing phase of gait.

\section{Results}

Fifty-nine subjects were screened for study enrollment and forty-five proceeded to randomization: 22 to TMR and 23 to TM (Fig. 1). The randomized groups were generally similar with respect to baseline variables (Table 1), however, more TMR participants used AFOs (61\% vs $36 \%$ ). Of those randomized, 7 patients (5 TMR and $2 \mathrm{TM}$ ) did not have baseline or follow-up measurements of the primary outcome variables. This was due to loss of interest in the study (3), transportation issues (1), aggravation of preexisting knee pain (2), and new onset of cardiac issues (1). These patients were excluded from the primary (modified) ITT analysis. Among those included in the ITT analysis, one patient who was randomized to the TM group actually received the TMR intervention, so was switched to the TMR group in the AT analysis. Also, among those included in the ITT analysis, 4 ( 1 in the TMR group and 3 in the TM group) did not participate in at least 6 exercise sessions are were excluded from the AT analysis. All those who participated in at least 6 sessions received 10 or more sessions.

Results for the primary outcome measures are present in Table 2a. There was no significant post-training ankle dorsiflexion or gait velocity differences between training groups based on the ITT analysis. Modest ankle DF kinematic improvements occurred in mean peak paretic DF swing angle $(4.84 ; 4.24 ; p=0.63)$ and DF angle at foot strike $(-0.70 ;-0.46 ; p=0.84)$ in TMR and TM respectively. The peak paretic DF swing angle gain was maintained at the first retention visit (6-week post training) for TMR and not TM. Gait velocity gains were similar post-training and a mean increase of $0.54 \mathrm{~m} / \mathrm{s}(\mathrm{p}=0.0030)$ and $0.56 \mathrm{~m} / \mathrm{s}(\mathrm{p}-0008)$ occurred in TMR and TM respectively. These differences between groups with respect to velocity gains failed to reach significance $(p=0.48)$. The velocity gains were durable and maintained through the second retention visit (3-months post training) in both groups.

For the as-treated cohort, no significant between group ankle dorsiflexion or gait velocity difference was seen. TMR had a larger peak paretic DF swing angle gain than TM at all time points but this did not reach statistical significance. The TMR post-training ankle DF angle at foot strike trended towards a significant within group improvement $(p=0.07)$. Gait velocity increases were similar and sustained throughout retention in both interventions.

\section{Sub-Analysis Results}

In the biomechanical foot drop cohort, the TMR group manifested a significant improvement in peak paretic DF swing angle $(n=6, p=0.0065)$ and this improvement was significantly better than that seen in the TMO group ( $n=2, p=0.028)$ (Table $2 b$.) Gait velocity gains occurred but failed to achieve significance. Regarding treatment fidelity, training adherence was greater for TMR and duration of treadmill training 
time was greater for TM (Table 3). Overall, TMR trained for fewer minutes per visit compared to TM, respectively $(22.0 ; 33.6 p=0.04)$.

\section{Discussion}

This randomized study in persons with chronic hemiparetic stroke found that ankle robotics integrated with treadmill training was not superior to a matched amount of treadmill training alone for clinically diagnosed foot drop. However, in a subset of individuals with more severe, biomechanically defined foot drop, TMR was more effective than TM alone to improve ankle dorsiflexion during unassisted overground walking. These findings suggest that the added benefits of human-robotics cooperative locomotor learning are related to neuromotor deficit severity, at least with respect to foot drop and robotassisted dorsiflexion.

\section{Foot Drop Outcomes}

These limited findings are consistent with other recent studies showing that lower extremity robotics rehabilitation control systems using assist-as-needed during locomotor style training have potential to improve gait function in persons with chronic hemiparetic stroke $[13,19,27,32]$. However, when considering the intention to treat analyses for all randomized persons with clinical foot-drop, there were no significant differences in ankle dorsiflexion outcomes. Only in our sub-analysis including those with ankle motor weakness defined by a peak DF angle less than $0^{\circ}$ at swing phase during gait, did we see a significant group by time improvement in ankle dorsiflexion biomechanics favoring TMR compared to TM. Our study population defined by clinically observable hemiparetic gait and symptoms of foot drop was potentially too broad a definition. As such, the wide-ranging variables influencing hemiparetic gait (i.e.: strength, spasticity, ROM, motor control, diminished sensation) may have limited identification of individuals with predominant ankle deficits amendable to this specific neuro-robotic approach. These findings suggest that a more rigorous biomechanical definition of foot drop for study inclusion may be needed to identify treatment responders versus non-responders.

\section{Gait Velocity Outcomes}

Gait velocity improved similarly in both groups by a range of approximately $11-15 \%$ for OG unassisted timed walks, similar to other studies showing that treadmill training translates into faster self-selected OG gait velocity in persons with chronic stroke [33-35]. Notably, our treatment fidelity tracking shows that the TMR group spent approximately $33 \%$ less time in actual training and trained at approximately $26 \%$ slower training velocities, compared to TM alone. These findings suggest that the dose-intensity characteristics of ankle robotics integrated treadmill training are different than those for TM alone to increase OG walking velocity, and indeed may be lower to produce comparable gains. While this study cannot determine the mechanisms for these differences, compensatory walking strategies are common poststroke and can produce functional walking speeds despite poor coordination of the paretic leg [36]. TMR and TM may improve walking speed by different compensatory strategies, which may impact dose- 
intensity of training and outcomes. Further studies are needed to understand differences in the doseintensity and efficiencies of robotics vs. non-robotics locomotor training after stroke.

\section{Study Limitations}

Study limitations include small sample size, inclusion of only chronic hemiparetic stroke, and likely inclusion criterion based on clinical diagnosis of foot drop rather than a stricter biomechanical definition. Additionally, training was limited to a targeted dorsiflexion-assist paradigm, leaving out potential benefits of training ankle plantarflexion for improved propulsion or inversion-eversion movements for improved mediolateral control and foot stability $[36,26]$.

\section{Conclusion}

We found that integrating adaptive ankle robotics into task-specific locomotor was not significantly better than treadmill training alone. Both interventions improved gait velocity. Therapeutic improvement in functional ankle dorsiflexion was seen for a small subset of subjects meeting strict criteria for biomechanically defined foot drop during ambulation. Further studies are needed to determine the specificity of robotics to improve gait as a function of deficit severity and recovery phase, including subacute stroke where reviews suggest exoskeleton training may confer added benefits [21].

\section{Abbreviations}

AFO, ankle foot orthosis; ANOVA, analysis of variance; A-P, anterior-posterior; AT, as treated analysis; BL Baseline, DF dorsiflexion, DOF, degrees of freedom; FES, functional electrical stimulation; ITT, intention to treat analysis; OG, over ground; ROM, range of motion; TM, treadmill training; TMR treadmill-integrated ankle robot training.

\section{Declarations}

\section{Ethics approval and consent to participate:}

University of Maryland, Baltimore Institutional Review Board and the Veterans Affairs Research and Development Committee approved the study (HP-00062671). Written informed consent was obtained from all participants. The research consent form included consent for data from the study to be published.

\section{Consent for publication:}

The research consent form included consent for data from the study to be published.

\section{Availability of data and materials:}


This clinical trial was prospectively registered on clinicaltrials.gov (Clinical Trial Identifier: NCT02483676) on June 29,2015 . Information on this study can found at https://clinicaltrials.gov/ct2/show/NCT02483676? term=anklebot $\&$ cond=Stroke\&cntry=US\&state=US\%3AMD\&city=baltimore \&draw=2\&rank=2

\section{Competing interests:}

The author(s) declared a potential conflict of interest (e.g. a financial relationship with the commercial organizations or products discussed in this article) as follows: Drs. A. Roy and R. Macko are listed as inventors on U.S. Patent Pending "Method and apparatus for providing deficit-adjusted adaptive assistance during movement phases of an impaired joint (application no.14/549.370) and hold equity positions in Next Step Robotics Inc., a company that manufactures a similar type of technology.

\section{Funding:}

This work was supported by Merit Review Award N1699-R from the United States (U.S.) Department of Veterans Affairs Rehabilitation Research and Development Service. This material is the result of work supported by the Baltimore VA Geriatric Research, Education, and Clinical Center (GRECC) and VA Maryland Health Care System, Baltimore, Maryland. The contents do not represent the views of the U.S. Department of Veterans Affairs or the United States Government.

\section{Authors' contributions:}

SC, AR, LM, DE, KF, ZK, RM Contributed to the conception and design of the study. SC, AR, LM, SK, RM interpreted the data and drafted the manuscript. LM also performed the data and statistical analysis. SC, $\mathrm{DE}, \mathrm{KF}, \mathrm{ZK}$ also carried out data collection. All authors read and approved the final manuscript.

\section{Acknowledgments}

The authors would like to thank Erica Cikanek for her contributions to data collection and study coordination.

\section{References}

1. Lin PY, Yang YR, Cheng SJ, Wang RY. The relation between ankle impairments and gait velocity and symmetry in people with stroke. Arch Phys Med Rehabil.2006;87:562-8.

2. Lauziere S, Mieville $C$, Betschart M, Aissaoui R, Nadeau S. Plantarflexor weakness is a determinant of kinetic asymmetry during gait in post-stroke individuals walking with high levels of effort. Clin Biomech. 2015; doi: 10.1016/j.clinbiomech.2015.07.004.

3. Woolley SM. Characteristics of Gait in Hemiplegia.Top Stroke Rehabil. 2001;7(4):1-18.

4. Lauziere S, Betschart M, Aissaoui R, Nadeau S. Understanding spatial and temporal gait asymmetries in individuals post stroke. Int J Phys Med Rehabil. 2014; doi:10.4172/2329- 
9096.100020

5. Bosch PR, Harris JE, Wing K. Review of therapeutic electrical stimulation for dorsiflexion assist and orthotic substitution from the American Congress of Rehabilitation Medicine Stroke Movement Interventions Subcommittee. Arch Phys Med and Rehab. 2014;95(2):390-6.

6. Ramnemark A, Nyberg L, Borssen B, Olsson T. Fractures after Stroke. Osteoporos Int. 1998; 8:92-5. doi:10.1007/s001980050053.

7. Dennis MS, Lo KM, McDowall M, West T. Fractures After Stroke: Frequency, Types, and Associations. Stroke. 2002; 33:728-34. doi:10.1161/hs0302.103621.

8. Ifejika-Jones N.L., Barrett A.M. Rehabilitation: Emerging Technologies, Innovative Therapies, and Future Objectives. Neurotherapeutics 2011; doi:10.1007/s13311-011-0057-x.

9. Kluding PM, Dunning K, O’Dell MW, Wu SS, Ginosian J, Feld J, et al. Foot drop stimulation versus ankle foot orthosis after stroke: 30-week outcomes. Stroke. 2013; 44:1660-9.

10. Sheffler LR, Bailey SN, Wilson RD, Chae J. Spatiotemporal, kinematic, and kinetic effects of a peroneal nerve stimulator versus an ankle foot orthosis in hemiparetic gait. Neurorehabil Neural Rep. 2013; 27:403-10.

11. Everaert DG, Stein RB, Abrams GM, Dromerick AW, Grancisco GE, Hafner BJ, et al. Effect of a footdrop stimulator and ankle-foot orthosis on walking performance after stroke: a multicenter randomized controlled trial. Neurorehabil Neural Rep. 2013; 27:579-91.

12. Hogan N. Impedance Control: An Approach to Manipulation," 1984 American Control Conference, San Diego, CA, USA, 1984. doi: 10.23919/ACC.1984.4788393.

13. Yeung L, Ockenfeld C, Pang M, Wai H, Soo O, Li S, Tong K. Randomized controlled trial of robotassisted gait training with dorsiflexion assistance on chronic stroke patients wearing ankle-footorthosis. J NeuroEngineering Rehabil. 2018; doi:10.1186/s12984-018-0394-7.

14. Roy A, Krebs HI, Barton JE, Macko RF, Forrester LW. Anklebot-assisted Locomotor Training after Stroke: A Novel Deficit-adjusted Control Approach. In: Proceedings IEEE Int Conf Rob Auto (ICRA), Karlsruhe, Germany: IEEE; 2013:2175-2182.

15. Duncan P W, Sullivan KJ, Behrman AL, Azen SP, Wu SS, Nadeau SE, et al. Bodyweight supported treadmill rehabilitation after stroke. N Engl J Med. 2011; 364:2026-36.

16. Nadeau SE, Wu SS, Dobkin BH, Azen SP, Rose DK, Tilson JK, et al. Effects of task-specific and impairment-based training compared with usual care on functional walking ability after inpatient stroke rehabilitation: LEAPS trial. Neurorehabil Neural Rep. 2013; 27:370-80.

17. Mayr A, Kofler M, Quirbach E, Matzak H, Fröhlich K, Saltuari L. Prospective, blinded, randomized crossover study of gait rehabilitation in stroke patients using the Lokomat gait orthosis. Neurorehabil Neural Rep. 2007; doi:10.1177/1545968307300697.

18. Horby TG, Campbell DD, Kahn JH, Demott T, Moore JL, Roth HR. Enhanced gait-related improvements after therapist versus robotic-assisted locomotor training in subjects with chronic stroke: a randomized controlled study. Stroke. 2008; 39:1786-92. 
19. Srivastava S, Kao P, Kim SH, Stegall P, Zanotto D, Higginson JS et al. Assist-as-needed robot-aided gait training improves walking function in individuals following stroke. IEEE Transactions on Neural Systems and Rehabilitation Engineering. 2015; 23 (6):956-963.

20. Hidler J, Nichols D, Pelliccio M, Brady K, Campbell DD, Khan JH, Horby TG. Multicenter randomized clinical trial evaluating the effectiveness of the Lokomat in subacute stroke. Neurorehabil Neural Rep. 2009; 23:5-13.

21. Louie DR, Eng JJ. Powered robotic exoskeletons in post-stroke rehabilitation of gait: a scoping review. J NeuroEngineering Rehabil. 2016; doi 10.1186/s12984-016-0162-5.

22. Dollar AM, Herr H. Lower Extremity Exoskeletons and Active Orthoses: Challenges and State-of-theArt," in IEEE Transactions on Robotics. 2008; 24(1):144-58.

23. Shorter KA, Xia J, Hsiao-Wecksler ET, Durfee WK, Kogler GF. Technologies for Powered Ankle-Foot Orthotic Systems: Possibilities and Challenges," in IEEE/ASME Transactions on Mechatronics. 2013; 18(1):337-47.

24. Alam M, Choudhury IA, Mamat AB. Mechanism and design analysis of articulated ankle foot orthoses for drop-foot. Scientific World Journal. 2014; doi:10.1155/2014/867869.

25. Forrester LW, Roy A, Krebs HI, Macko RF. Ankle training with a robotic device improves hemiparetic gait after a stroke. Neurorehabil Neural Rep. 2011; 25:369-77.

26. Forrester LW, Roy A, Goodman RN, Rietschel J, Barton JE, Krebs HI, et al. Clinical application of a modular ankle robot for stroke rehabilitation. NeuroRehabilitation. 2013; 33(1): 85-97.

27. Forrester LW, Roy A, Hafer-Macko C, Krebs HI, Macko RF. Task-specific ankle robotics gait training after stroke: a randomized pilot study. J NeuroEngineering Rehabil. 2016; doi: 10.1186/s12984-0160158-1.

28. Dalgas U, Severinsen K, Overgaard K. Relations between 6-minute walking distance and 10-meter walking speed in patients with multiple sclerosis and stroke. Archives of Physical Medicine and Rehabilitation. 2012; 93(7):1167-72.

29. Williams N. The Borg Rating of Perceived Exertion (RPE) scale. Occupational Medicine. 2017; doi:10.1093/occmed/kqx063.

30. Roy A, Krebs HI, Williams DJ, Bever CT, Forrester LW, Macko RF, et al. Robot-aided neurorehabilitation: a robot for ankle rehabilitation. IEEE Trans Rob. 2009; 25:569-82.

31. Magder L. Modelling the Covariance. In: Fitzmaurice GM, Laird NM, Ware JH. Applied Longitudinal Analysis $2^{\text {nd }}$ Wiley; 2011. p.168.

32. Seo JS, Yang HS, Jung S, Kang CS, Jang S, Kim DH. Effect of reducing assistance during robotassisted gait training on step length asymmetry in patients with hemiplegic stroke: A randomized controlled pilot trial. Medicine (Baltimore). 2018; doi: 10.1097/MD.0000000000011792.

33. Macko RF, Ivey FM, Forrester LW. Task-oriented aerobic exercise in chronic hemiparetic stroke: training protocols and treatment effects. Top Stroke Rehabil. 2005; 12:45-7. 
34. Liston R, Mickelborough J, Harris B, Hann WE, Tallis, RC. Conventional physiotherapy and treadmill re-training for higher-level gait disorders in cerebrovascular disease. Age and Ageing. 2000; 29 (4):311-18. doi:10.1093/ageing/29.4.311.

35. Mehrholz J, Thomas S, Elsner B. Treadmill training and body weight support for walking after stroke. Cochrane Database of Systematic Reviews. 2017; doi: 10.1002/14651858.CD002840.pub4.

36. Bowden MG, Balasubramanian CK, Neptune RR, Kautz SA. Anterior-posterior ground reaction forces as a measure of paretic leg contribution in hemiparetic walking. Stroke. 2006; 37:872-6.

\section{Tables}

Table 1: Participant demographics

\begin{tabular}{|c|c|c|}
\hline Characteristic & $\begin{array}{c}\text { TMR } \\
(n=23)\end{array}$ & $\begin{array}{c}\text { TM } \\
(\mathrm{n}=22)\end{array}$ \\
\hline $\begin{array}{l}\text { Sex } \\
\text { Male } \\
\text { Female } \\
\end{array}$ & $\begin{array}{c}14(61 \%) \\
9(39 \%) \\
\end{array}$ & $\begin{array}{c}14(64 \%) \\
8(36 \%) \\
\end{array}$ \\
\hline $\begin{array}{l}\text { Race } \\
\text { African American } \\
\text { Asian } \\
\text { Caucasian } \\
\end{array}$ & $\begin{array}{c}15(65 \%) \\
2((\%) \\
6(23 \%) \\
\end{array}$ & $\begin{array}{c}15(68 \%) \\
1(5 \%) \\
6(27 \%) \\
\end{array}$ \\
\hline $\begin{array}{l}\text { Age } \\
30-44 \\
45-59 \\
60-74 \\
75+ \\
\end{array}$ & $\begin{array}{c}2(9 \%) \\
6(26 \%) \\
14(61 \%) \\
1(4 \%) \\
\end{array}$ & $\begin{array}{c}2(9 \%) \\
8(36 \%) \\
10(45 \%) \\
2(9 \%) \\
\end{array}$ \\
\hline $\begin{array}{l}\text { Years since stroke } \\
\quad<2 \\
2-4 \\
4-6 \\
6+ \\
\end{array}$ & $\begin{array}{l}4(18 \%) \\
7(30 \%) \\
4(17 \%) \\
8(35 \%) \\
\end{array}$ & $\begin{array}{l}2(9 \%) \\
9(41 \%) \\
7(32 \%) \\
4(18 \%) \\
\end{array}$ \\
\hline $\begin{array}{l}\text { Paretic Side } \\
\text { Left } \\
\text { Right } \\
\end{array}$ & $\begin{array}{c}16(70 \%) \\
7(30 \%)\end{array}$ & $\begin{array}{c}13(59 \%) \\
9(41 \%)\end{array}$ \\
\hline $\begin{array}{l}\mathrm{AFO} \\
\text { No } \\
\text { Yes }\end{array}$ & $\begin{array}{c}9(39 \%) \\
14(61 \%)\end{array}$ & $\begin{array}{c}14(64 \%) \\
8(36 \%)\end{array}$ \\
\hline $\begin{array}{l}\text { Assistive Device (AD) } \\
\text { No } \\
\text { Yes }\end{array}$ & $\begin{array}{c}4(17 \%) \\
19(83 \%)\end{array}$ & $\begin{array}{c}7(32 \%) \\
15(68 \%)\end{array}$ \\
\hline $\begin{array}{l}\text { Walking Speed without AD }(\mathrm{m} / \mathrm{s}) \\
\text { Unable to walk without AD } \\
\text { Limited ambulator }(<0.2 \mathrm{~m} / \mathrm{s}) \\
\text { Household }(0.2-0.4 \mathrm{~m} / \mathrm{s}) \\
\text { Limited Community }(0.4-0.8 \mathrm{~m} / \mathrm{s}) \\
\text { Community }(>1.3 \mathrm{~m} / \mathrm{s})\end{array}$ & $\begin{array}{c}6(26 \%) \\
0 \\
4(17 \%) \\
5(22 \%) \\
8(35 \%)\end{array}$ & $\begin{array}{l}4(18 \%) \\
3(14 \%) \\
3(14 \%) \\
10(45 \%) \\
10(9 \%)\end{array}$ \\
\hline
\end{tabular}

Abbreviations: $A D$ Assistive device, $A F O$ ankle foot orthosis, $\mathrm{m} / \mathrm{s}$ meters per second, $T M$ Treadmill training, $T M R$ Treadmill-integrated ankle robot training.

Table 2. Outcome results for the (a) primary and (b) sub-analysis. 


\begin{tabular}{|c|c|c|c|c|c|c|c|c|c|c|c|}
\hline a. & & \multicolumn{4}{|c|}{ Intention-to-treat cohort } & & \multicolumn{4}{|c|}{ As-treated cohort } & \\
\hline \multirow[t]{2}{*}{ Measure } & \multirow{2}{*}{$\begin{array}{l}\text { Time } \\
\text { Point }\end{array}$} & \multicolumn{2}{|c|}{ TMR $(n=17)$} & \multicolumn{2}{|c|}{$\mathrm{TM}(\mathrm{n}=21)$} & \multirow{2}{*}{$\begin{array}{l}P- \\
\text { value }^{2}\end{array}$} & \multicolumn{2}{|c|}{ TMR $(n=17)$} & \multicolumn{2}{|c|}{$\mathrm{TM}(\mathrm{n}=18)$} & \multirow{2}{*}{$\begin{array}{l}P \text { - } \\
\text { value }^{2}\end{array}$} \\
\hline & & $\begin{array}{l}\text { Mean } \\
(\mathrm{SD}) \\
\end{array}$ & $\begin{array}{l}P \text { - } \\
\text { value }^{1} \\
\end{array}$ & $\begin{array}{l}\text { Mean } \\
\text { (SD) }\end{array}$ & $\begin{array}{l}P \text { - } \\
\text { value }^{1}\end{array}$ & & $\begin{array}{l}\text { Mean } \\
\text { (SD) }\end{array}$ & $\begin{array}{l}P \text { - } \\
\text { value }^{1}\end{array}$ & $\begin{array}{l}\text { Mean } \\
\text { (SD) }\end{array}$ & $\begin{array}{l}P \text { - } \\
\text { value }^{1}\end{array}$ & \\
\hline \multirow{4}{*}{$\begin{array}{l}\text { Peak Paretic } \\
\text { DF Swing } \\
\text { Angle }\end{array}$} & $\mathrm{BL}$ & $\begin{array}{l}3.95 \\
(6.83)\end{array}$ & & $\begin{array}{l}3.95 \\
(6.83)\end{array}$ & & & $\begin{array}{l}3.86 \\
(7.11)\end{array}$ & & $\begin{array}{l}3.86 \\
(7.11)\end{array}$ & & \\
\hline & Post & $\begin{array}{l}4.84 \\
(6.83)\end{array}$ & 0.32 & $\begin{array}{l}4.24 \\
(6.83)\end{array}$ & 0.73 & 0.63 & $\begin{array}{l}5.06 \\
(7.11)\end{array}$ & 0.17 & $\begin{array}{l}3.81 \\
(7.11)\end{array}$ & 0.95 & 0.30 \\
\hline & RET1 & $\begin{array}{l}4.34 \\
(6.26) \\
\end{array}$ & 0.58 & $\begin{array}{l}3.27 \\
(6.26) \\
\end{array}$ & 0.38 & 0.29 & $\begin{array}{l}4.33 \\
(6.49) \\
\end{array}$ & 0.51 & $\begin{array}{l}3.12 \\
(6.49) \\
\end{array}$ & 0.34 & 0.23 \\
\hline & RET2 & $\begin{array}{l}3.33 \\
(6.72) \\
\end{array}$ & 0.56 & $\begin{array}{l}3.43 \\
(6.72) \\
\end{array}$ & 0.62 & 0.95 & $\begin{array}{l}3.40 \\
(6.95) \\
\end{array}$ & 0.66 & $\begin{array}{l}3.18 \\
(6.95) \\
\end{array}$ & 0.52 & 0.88 \\
\hline \multirow[t]{4}{*}{$\begin{array}{l}\text { DF Angle at } \\
\text { Foot Strike }\end{array}$} & $\mathrm{BL}$ & $\begin{array}{l}-1.83 \\
(5.03) \\
\end{array}$ & & $\begin{array}{l}-1.83 \\
(7.31) \\
\end{array}$ & & & $\begin{array}{l}-1.49 \\
(4.66) \\
\end{array}$ & & $\begin{array}{l}-1.49 \\
(7.56) \\
\end{array}$ & & \\
\hline & Post & $\begin{array}{l}-0.70 \\
(6.55)\end{array}$ & 1.12 & $\begin{array}{l}-0.46 \\
(5.70)\end{array}$ & 1.37 & 0.84 & $\begin{array}{l}-0.13 \\
(6.20)\end{array}$ & 0.065 & $\begin{array}{l}-0.54 \\
(5.90)\end{array}$ & 0.31 & 0.74 \\
\hline & RET1 & $\begin{array}{l}-2.18 \\
(6.27) \\
\end{array}$ & -0.36 & $\begin{array}{l}-2.15 \\
(6.16) \\
\end{array}$ & -0.32 & 0.97 & $\begin{array}{l}-1.79 \\
(5.95) \\
\end{array}$ & 0.72 & $\begin{array}{l}-1.20 \\
(6.39) \\
\end{array}$ & 0.38 & 0.84 \\
\hline & RET2 & $\begin{array}{l}2.99 \\
(5.96)\end{array}$ & -1.16 & $\begin{array}{l}-1.58 \\
(6.71)\end{array}$ & 0.25 & 0.31 & $\begin{array}{l}2.56 \\
(5.75)\end{array}$ & 0.32 & $\begin{array}{l}-1.44 \\
(6.93)\end{array}$ & 0.95 & 0.42 \\
\hline \multirow[t]{4}{*}{$\begin{array}{l}\text { Gait Velocity }^{2} \\
(\mathrm{~m} / \mathrm{s})\end{array}$} & $\mathrm{BL}$ & $\begin{array}{l}0.48 \\
(0.21) \\
\end{array}$ & & $\begin{array}{l}0.48 \\
(0.34)\end{array}$ & & & $\begin{array}{l}0.49 \\
(0.21) \\
\end{array}$ & & $\begin{array}{l}0.49 \\
(0.35)\end{array}$ & & \\
\hline & Post & $\begin{array}{l}0.54 \\
(0.24)\end{array}$ & 0.0030 & $\begin{array}{l}0.56 \\
(0.32) \\
\end{array}$ & 0.0008 & 0.48 & $\begin{array}{l}0.54 \\
(0.24) \\
\end{array}$ & 0.0080 & $\begin{array}{l}0.57 \\
(0.33) \\
\end{array}$ & 0.0015 & 0.31 \\
\hline & RET1 & $\begin{array}{l}0.53 \\
(0.24) \\
\end{array}$ & 0.052 & $\begin{array}{l}0.55 \\
(0.33) \\
\end{array}$ & 0.0017 & 0.54 & $\begin{array}{l}0.53 \\
(0.24) \\
\end{array}$ & 0.11 & $\begin{array}{l}0.56 \\
(0.34) \\
\end{array}$ & 0.0019 & 0.30 \\
\hline & RET2 & $\begin{array}{l}0.52 \\
(0.23) \\
\end{array}$ & 0.052 & $\begin{array}{l}0.59 \\
(0.34) \\
\end{array}$ & 0.0014 & 0.10 & $\begin{array}{l}0.53 \\
(0.23) \\
\end{array}$ & 0.041 & $\begin{array}{l}0.58 \\
(0.36) \\
\end{array}$ & 0.0114 & 0.23 \\
\hline
\end{tabular}

\begin{tabular}{|c|c|c|c|c|c|c|}
\hline b. & & \multicolumn{4}{|c|}{ Biomechanical foot drop cohort } & \\
\hline Measure & \multirow[t]{2}{*}{ Time Point } & \multicolumn{2}{|l|}{ TMR $(n=6)$} & \multicolumn{2}{|l|}{$\mathrm{TM}(\mathrm{n}=2)$} & \multirow[t]{2}{*}{$P$-value ${ }^{2}$} \\
\hline & & Mean (SD) & $P$-value ${ }^{1}$ & Mean (SD) & $P$-value ${ }^{1}$ & \\
\hline \multirow{4}{*}{ Peak Paretic DF Swing Angle } & BL & $-4.98(3.59)$ & & $-4.98(3.59)$ & & \\
\hline & Post & $-1.29(5.41)$ & 0.0065 & $-6.07(5.41)$ & 0.52 & 0.028 \\
\hline & RET1 & $-2.58(3.90)$ & 0.11 & $-2.88(3.90)$ & 0.38 & 0.91 \\
\hline & RET2 & $-3.80(3.06)$ & 0.45 & $-3.41(3.06)$ & 0.50 & 0.87 \\
\hline
\end{tabular}

${ }^{1} P$-value for statistical significance of change from baseline within group based on a longitudinal regression model.

${ }^{2} P$-value for statistical significance of difference between groups based on a longitudinal regression model.

${ }^{3}$ Gait Velocity measured either using or not using an assistive device.

Abbreviations: $B L$ baseline, $D F$ dorsiflexion, $S D$ standard deviation, $R E T 1$ Retention visit one at 6 weeks post-training, RET2 Retention visit two at 3 months post-training, $T M$ treadmill training, $T M R$ Treadmill-integrated ankle robot training.

Table 3. Training adherence and performance parameters 


\begin{tabular}{|l|c|c|c|c|}
\hline Parameter & Group & Median & Min/Max & $P$-value $^{1}$ \\
\hline \multirow{2}{*}{ Number of visits } & TMR & 18 & $18 / 18$ & \multirow{2}{*}{0.013} \\
\cline { 2 - 4 } & TM & 18 & $3 / 18$ & \\
\hline \multirow{2}{*}{ Duration (minutes) } & TMR & 22.0 & $13 / 17$ & \multirow{2}{*}{0.040} \\
\cline { 2 - 4 } & TM & 33.6 & $10.7 / 52.3$ & \\
\hline Treadmill Speed (mph) & TMR & 1.01 & $0.21 / 1.48$ & \multirow{2}{*}{0.068} \\
\cline { 2 - 4 } & TM & 1.41 & $0.26 / 2.98$ & \\
\hline \multirow{2}{*}{ Heart Rate (bpm) } & TMR & 109.4 & $76.2 / 141.2$ & \multirow{2}{*}{0.37} \\
\cline { 2 - 4 } & TM & 107.7 & $75.2 / 135.0$ & \\
\hline
\end{tabular}

${ }^{1} P$-value based on a two-sample Wilcoxon test using a t-approximation.

Abbreviations: $b p m$ beats per minute, $m p h$ miles per hour, $T M R$ Treadmill-

integrated ankle robot training,

$T M$ treadmill training.

Figures 
Excluded ( $n=14$ )

- Did not meet inclusion criteria ( $n=10$ )

- Declined to participate $(n=4)$

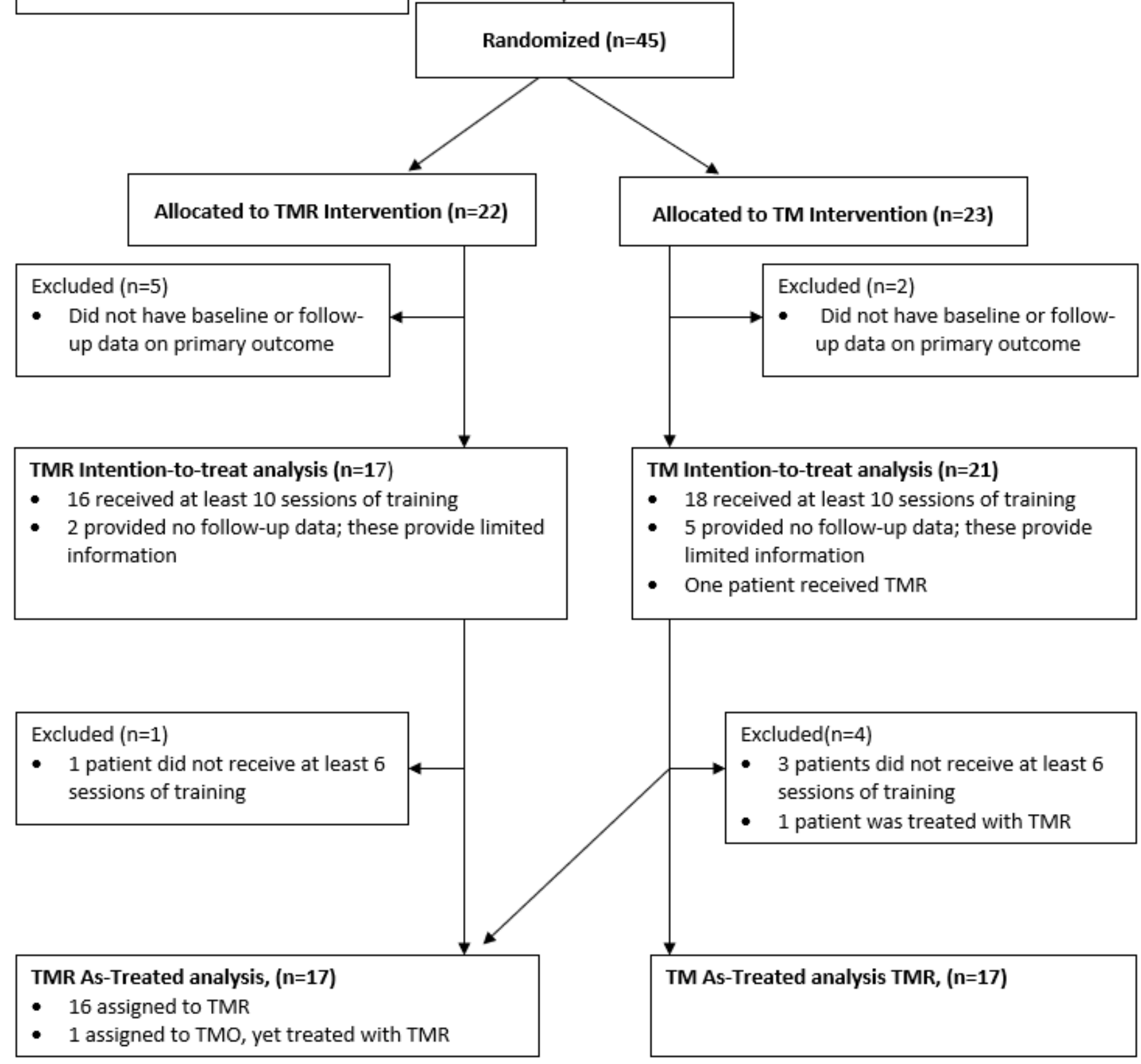

\section{Figure 1}

CONSORT diagram 